\title{
The Return of the Fifties: Trends in College Students' Values Between 1952 and 1984
}

\author{
Dean R. Hoge \\ Catbolic University of America \\ Jann L. Hoge \\ University of Michigan \\ Janet Wittenberg \\ Dartmouth College
}

Five identical surveys were carried out in 1952, 1968-1969, 1974, 1979, and 1984 among undergraduate men at Dartmouth College and the University of Michigan to measure value trends. In most value domains the trends are U-shaped, showing that the trends from the fiftics to the sixties and seventies have reversed, and attitudes in 1984 were either similar to the fifties or moving in that direction. The domains include traditional religion, career choice, faith in government and the military, advocacy of social constraints on deviant social groups, attitudes about free enterprise, government and economics, sexual morality, marijuana use, and personal moral obligations. Two attitude areas do not show a return of the fifties: (1) other-direction was high in 1952, then dropped to the sixties and did not rise; (2) the level of politicization rose greatly from 1952 to the sixties, then dropped again only slightly.

College student value trends have been researched for some decades, and the results have been valuable to both educators and sociologists. Sociologists gain knowledge about social change; Yankelovich (1974) argues that college students are a kind of forerunner group for innovation and that the basic pattern of cultural change in America is diffusion from college students and recent graduates to the rest of the population.

Researchers agree on the main outlines of value trends among students. The 1930 s were a time of social, political, and religious liberalism.

\footnotetext{
- The 1984 data collection was supported by the Spencer Foundation. Earlier data collections were supported by the Spencer Foundation and the Center for the Study of Youth Development, Catholic University. We would like to thank John McCarthy, David Lecge, and Douglas Sloane for assistance. Address correspondence to Dr. Dean Hoge, Center for the Study of Youth Development, The Catholic University of America, Washington, DC 20064 .
}

(C) 1987 by the Eastern Sociological Society. All rights reserved. 0884-8971/87/0203-0500\$1.50 
Beginning in about 1939 or 1940, a new era of conservatism began, and by the early 1950 s college students were privatistic, conventional in attitudes and behavior, and traditional in religious views. The highpoint of traditional religious commitment was about 1952-1955 (Hoge, 1974). At that time protest movements were absent from campuses (Jacob, 1957; Goldsen et al., 1960).

After the Khrushchev and early Eisenhower years, Cold War anxieties abated, and by the end of the 1950 s there was evidence of identity diffusion on many campuses. It was then that Erik Erikson's diagnosis of the "identity crisis" among youth (1959) had its greatest persuasiveness. Earlier certainties were no longer firm. Soon afterward the movements of the 1960s appeared. First came the beatniks, then the civil rights movement, the New Left, the hippies, and the anti-war movement. A great deal of research was done to explain the alienation and rebellion (for overviews see Foster and Long, 1970; Flacks, 1971; Lipset, 1971).

By the middle 1970 s there was evidence of a trend toward conservatism in political, economic, and religious attitudes. The lowpoint in traditional religious attitudes was about 1972-1975. Two sets of replication studies provide good data about the 1970 s and early 1980 s. The first is the annual freshman survey sponsored by the American Council on Education. It has been administered each fall since 1967 on about three hundred campuses (see Astin et al., 1985). Several value items have been replicated yearly, and the main trends are an increase in privatism and a decrease in broader social concerns from the early $1970 \mathrm{~s}$ to the middle 1980 s. The increased privatism is seen, first, in the greater percentages who say that financial well-being is important in their lives. In 1968, 41 percent said this; in 1974 it was 46 percent, in 1978 it was 60 percent, and in 1984 it was 72 percent. Second, after a lowpoint in 1974, freshmen increased their interest in raising a family; in 1974, 55 percent said it was important, and by 198470 percent said so. Third, the perceived importance of gaining personal recognition for work in one's field rose sharply after about 1972.

The decreased social concerns are seen in (a) the diminished interest in keeping up with political affairs between the late 1960s and the middle 1970s; (b) the decreased interest in developing a philosophy of life ( 76 percent said this was important in 1970 , compared with 48 percent in 1984); and (c) the decreased interest in environmental cleanup and concern about overpopulation. Also, support for legalizing marijuana and abortion weakened after the middle 1970s, and support for the death penalty grew (see Hartle and Taylor, 1985).

The new element in the early 1980s appears to be a turn toward conservative attitudes in the area of personal morals-a trend that was not yet visible in the 1970s. This new development is also seen in the second series of replications, that of high school seniors in about 130 


\section{Sociological Forum}

schools around the nation (see Johnston, Bachman, and O'Malley, 1985). As in the college freshman replications, the importance to the high school seniors of making lots of money increased from 1976 to 1983 (from 15 percent saying it was important in 1976 to 23 percent in 1983), and the importance of being successful in one's line of work increased (from 53 percent to 61 percent) in the same time. Willingness to limit future family size due to world overpopulation fell from 34 percent in 1976 to 27 percent in 1983 . And, similar to the college freshmen, support for legalizing marijuana use fell from 33 percent to 19 percent between 1976 and 1983. Self-reported drug use gradually declined after a highpoint in 1978-1979.

A number of smaller replication studies have been done on specific topics. Beginning in the late 1970 s and continuing into the early 1980s, there was decreased support for legalizing marijuana use (Carter and Sedlacek, 1983; Hastings and Hoge, 1986) and decreased willingness to limit family size due to world overpopulation (Cook, West, and Hamner, 1982; Hastings and Hoge, 1986). The trends toward politically conservative attitudes and religious orthodoxy seemed to continue into the early 1980s (also see Levine, 1980; Martinez and Sedlacek, 1983; Manese and Sedlacek, 1983; Hildebrand and Abramowitz, 1984; Katchadourian and Boli, 1985).

The present paper reports trends found in a series of replication studies between 1952 and 1984 .

\section{PROCEDURE}

In 1952 the Cornell Values Study group carried out an extensive survey of male students in eleven colleges and universities across the nation. Questionnaires were given to random samples of undergraduate men in each institution with about 85 percent completion (Goldsen et al., 1960). In 1968-1969 replication studies were carried out in two of the colleges, Dartmouth and the University of Michigan, using about fifty identical items (Hoge, 1974). The Dartmouth replication surveyed a stratified random sample of 400 undergraduate men in April and May 1968 with a 91 percent completion rate. The Michigan replication used a stratified random sample of 450 men in February and March 1969 with an 89 percent completion rate.

In spring 1974 a second replication was done at Dartmouth and at Michigan, using the same methodology. The survey of Dartmouth men had an 84 percent completion rate, and the survey of Michigan men had a 78 percent completion rate, producing 366 and 348 cases respectively.

In spring 1979 a third replication was done at each school. The survey had a 70 percent completion rate at Dartmouth and a 76 percent 
completion rate at Michigan, producing 316 and 331 cases respectively (Hoge, Luna, and Miller, 1981). In spring 1984 a fourth replication was done. The survey at Dartmouth had a 67 percent completion rate and that at Michigan had a 77 percent completion rate, producing 234 and 364 cases respectively.

In all the surveys, identical questionnaire items and sampling methods were used, and near-identical data collection methods were used. Variations in completion rates resulted mostly from differences in follow-up efforts.

A number of veterans were in the Michigan sample-17 percent in 1952,3 percent in 1969,5 percent in 1974, and less than 1 percent in 1979 and 1984 . For sake of comparability of data, all veterans were deleted from the sample in 1952, 1969, and 1974. At Dartmouth the number of veterans was never high-6 percent in 1952 and less than 1 percent thereafter; thus they were not deleted. We also investigated the students' backgrounds at both colleges so that we could weight the data to eliminate changes in college recruiting practices causing changes in the student bodies. In this report we look at raw data first, then we discuss the weighting method and weighted data.

\section{FINDINGS}

Value changes will be reviewed in seven areas: personal commitments; traditional religion; other-direction; misanthropy, anomie, and alienation; attitudes toward social constraints on certain groups; attitudes on economics and government; and personal morals.

\section{Personal Commitments}

We begin by looking at indicators of overall personal commitments of the students. Table 1 gives data for six areas of personal commitment. Respondents were asked to rank three areas as first, second, and third most important.

Among both Dartmouth and Michigan students in all the surveys, family relationships and career or occupation were seen as promising the most life satisfactions. The modal response has family ranked first, career second, and leisure-time activities third. A few significant trends are visible. ${ }^{1}$ Family life as a source of satisfaction dropped in importance from 1952 to 1974 , then rose again in 1979 and 1984. Career dropped

\footnotetext{
${ }^{x}$ Throughout this report whenever any two studies are compared, differences significant at .05 are: for percentages in the ranges from 0 to 20 or 80 to 100 , about 5 percentage points; for percentages in the range from 20 to 80 , about 8 points. These differences apply for both Dartmouth and Michigan, even though the sample sizes are larger in the earlier Michigan studies.
} 


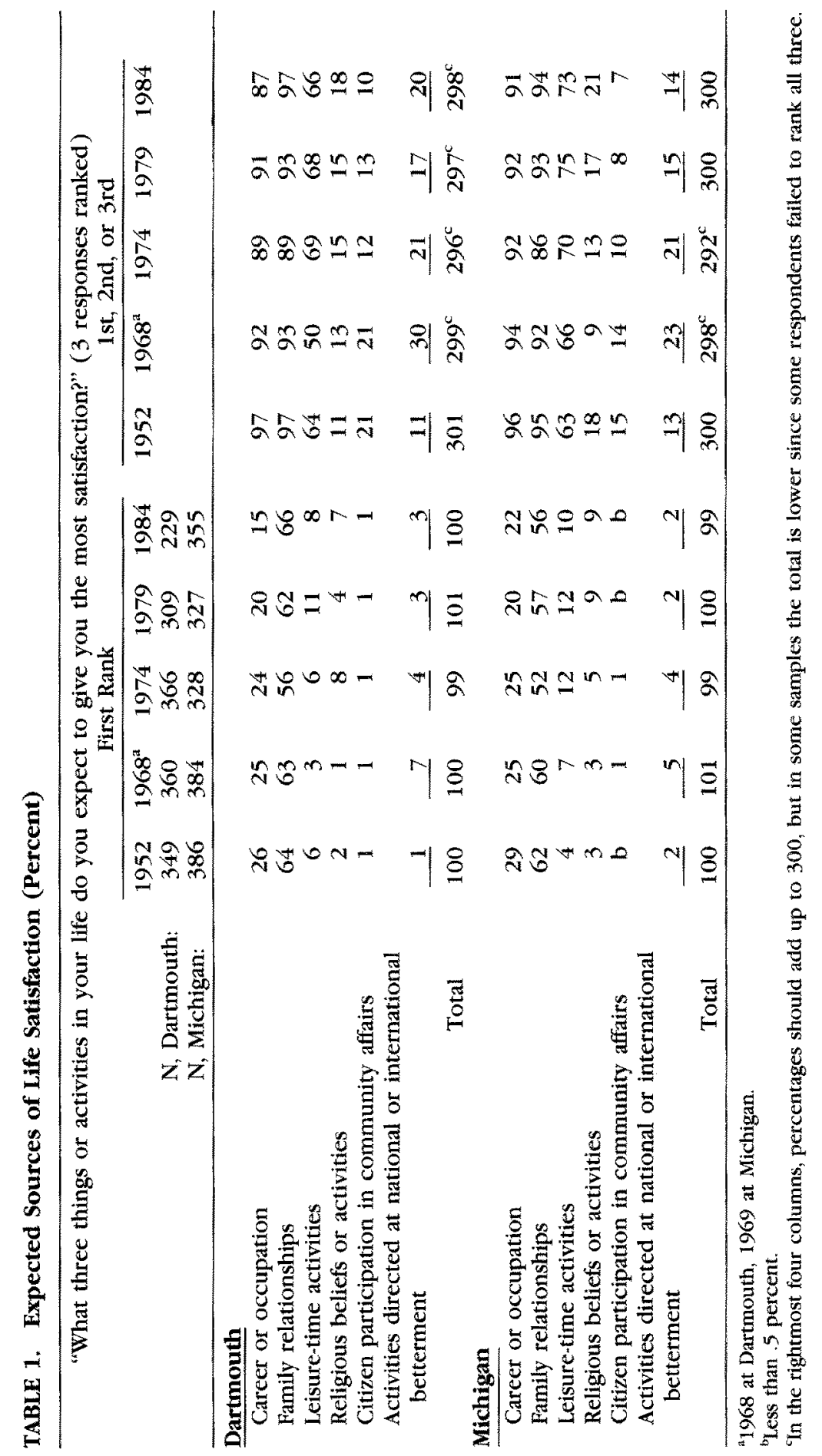


in importance at Dartmouth after 1974. Leisure increased in importance, especially during the 1970 s. Both forms of social participation (local community participation and activities directed at national or international betterment) declined in importance after 1968 .

An important concept is "privatism," defined as a commitment pattern remaining almost wholly within the immediate family, leisure, and occupational spheres, oblivious to broader social or ideological interests (Feldman and Newcomb, 1969:11-15). An indicator of privatism is the difference between the mean of the first three responses and the mean of the last two responses, when all rankings are included. ${ }^{2}$ At both colleges privatism was lowest in 1968-1969 and second lowest in 1974. In 1952 it was somewhat higher, and in 1979 and 1984 it again resembled the 1952 level.

The high rating of activities directed at national betterment at Dartmouth in 1968 is probably a result of the excitement surrounding the Eugene McCarthy movement. The 1968 survey was taken near the New Hampshire primary date, when Eugene McCarthy was attracting strong student support for his anti-war position.

Another indicator of privatism was an item asking, "Do you ever get as worked up about something that happens in politics or public affairs as you do about something that happens in your personal life?" The percentages saying $n o$ in the five surveys at Dartmouth were 61, 32, 39, 33, and 32. The percentages at Michigan were 63, 29, 40, 40, and 39. By this indicator the level of privatism fell greatly from 1952 to $1968-1969$, then rose again only slightly in the years following.

A third indicator of personal commitments is career choice after graduation. A question asked about this in all the surveys. The most important trend occurred in the percent interested in business careers, either in their own businesses or others. Interest in a business career dropped sharply from 1952 to 1974 , then increased greatly in 1979 and stayed about the same in 1984 (data not shown here).

\section{Traditional Religion}

Table 2 reports on three items on religious beliefs and behavior. The percentage of students saying they have no religious preference was highest in 1974, then it dropped sharply. Belief in a Divine God, Creator of the universe, dropped from 1952 to 1968 , then rose again beginning in 1979 and continuing to rise in 1984. Church attendance dropped sharply from 1952 to $1968-1969$, then rose gradually at Dartmouth but not at Michigan. In short, traditional religion weakened between 1952

${ }^{2}$ The item has six responses, but "religious beliefs or activities" does not seem to be an indicator of either privatism or politicization, based on correlation analyses of all six responses. 


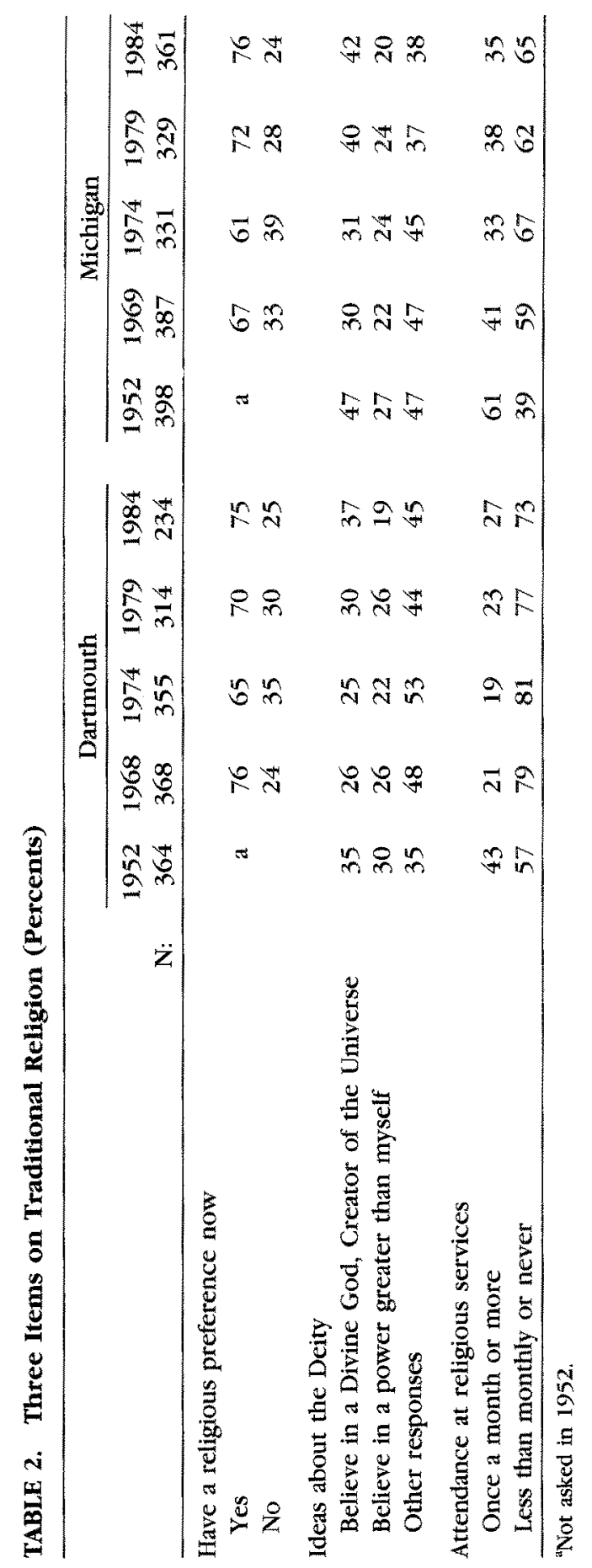


and 1968 , but beginning in 1979 it became markedly stronger, and it continued to strengthen to 1984 .

At Michigan an additional item asked about belief in immortality. The percentage believing in personal immortality (the continued existence of the individual soul) was thirty-three in 1969, twenty-nine in 1974, thirty-five in 1979, and thirty-seven in 1984. Again we see strengthened belief beginning in 1979 .

\section{Other-Direction}

The 1952 researchers were interested in other-direction as defined by Riesman, Glazer, and Denney (1950), that is, a personal orientation to the opinions of other people as a guide to one's own attitude or behavior. Two items were used as indicators: in the first item the measure of other-direction is the selection of "having a pleasant personality" as a quality needed for success. It dropped in importance very much from 1952 to 1969 , then continued dropping at Michigan but only slightly at Dartmouth. The second item, "How important is it to you that different people like you," has the same pattern of a sharp drop from 1952 to 1968-1969, but with little change since then.

Other-direction was obviously strong in the 1950 s, but it was a product of the social climate at that time, not a permanent characteristic of American values. Since the 1950 s it has been much weaker, and even in the conservative climate of the middle 1980s, it is not returning.

\section{Misanthropy, Anomie, and Alienation}

The 1952 questionnaire included Rosenberg's (1957) five-item Misanthropy Scale and Srole's (1956) five-item Anomie Scale. The replication studies included three items from each plus two items measuring alienation from government. (See Table 3.) On the misanthropy items the only noteworthy change common to both colleges was a decline after 1952 in the percentage agreeing that "human nature is fundamentally cooperative"; otherwise no trend is visible. On the anomie items no overall trends are visible at all.

The items on alienation from the government at the bottom of Table 3 show distinct trends. Alienation from the government and the military was much higher in 1974 than earlier or later. Beginning in 1979 it weakened again and dropped sharply to 1984 . In 1984 feelings about the military were similar to those in 1952.

The set of items in Table 3 demonstrates that specific areas of alienation are highly subject to historical events and government policies, whereas more general feelings of misanthropy or anomie are not. 


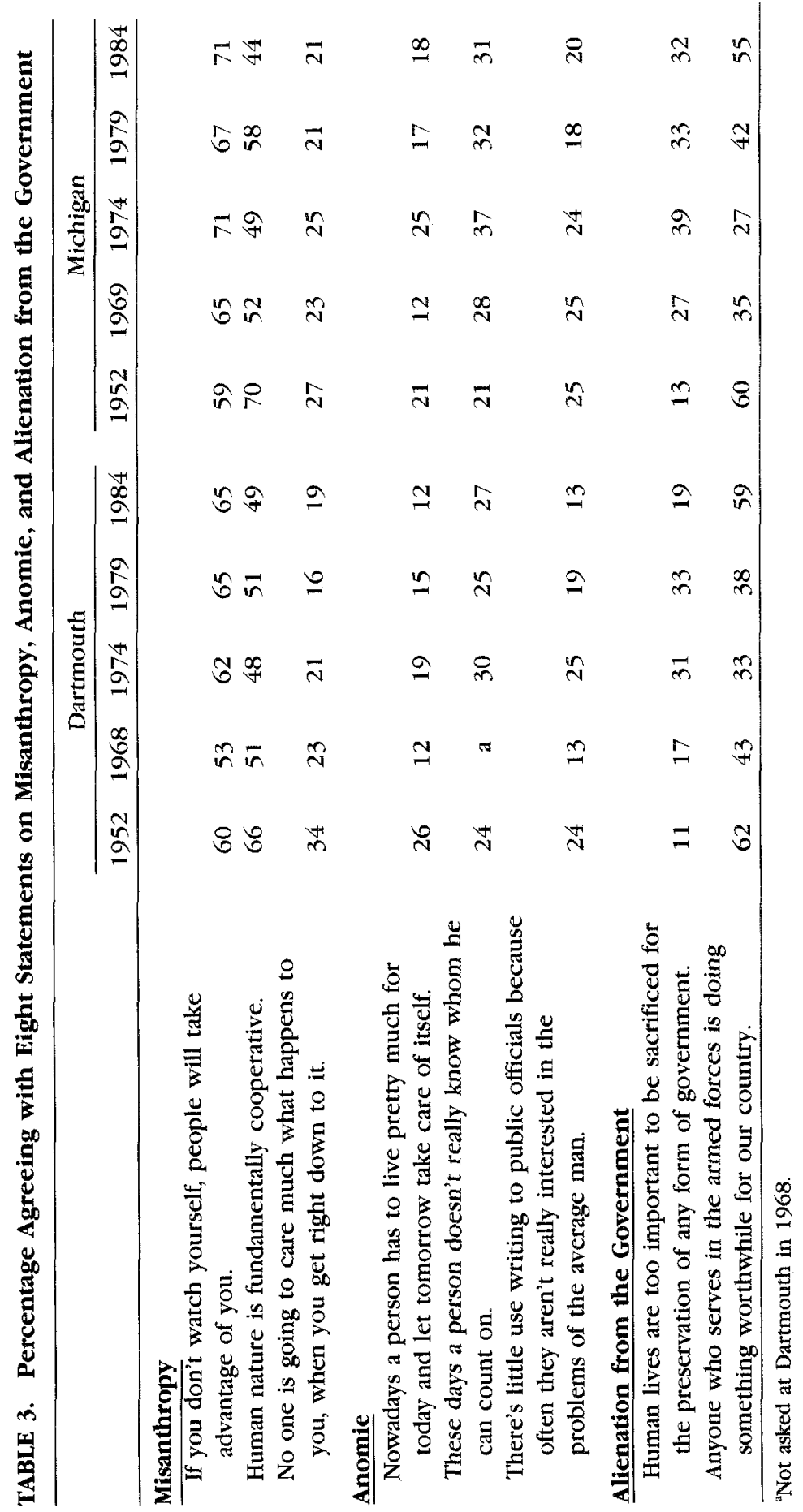




\section{Atittudes Toward Social Constraints}

Panel A of Table 4 includes responses to six items concerning social constraints on possibly-deviant individuals and groups. The overall pattern is a sharp decline from 1952 to $1968-1969$ in the call for constraining such groups, then a mild renewal beginning in 1979 and an increase from 1979 to 1984 . Apparently in the new conservative climate the students feel more anxiety about such groups and less concern about civil liberties.

\section{Attitudes Toward Economics and Government}

Panel $B$ of Table 4 includes eight items on free enterprise and government. The first four state central free enterprise attitudes, and trends on all four are the same-agreement dropping from 1952 to 1974 , then rising again from 1974 to 1984 but not to the 1952 level.

The fifth item, in support of labor unions, decreased from 1952 to 1968-1969, then had little change to 1984 .

The sixth and seventh items, on small government and government planning, had irregular trend lines difficult to interpret. Apparently, the argument that "government planning results in the loss of freedom" is not closely associated with the free-enterprise ideology stated earlier in this panel. ${ }^{3}$

The last item was asked only in 1974, 1979, and 1984. It shows a remarkably steep trend in ten years-a reduction of 32 percentage points at Dartmouth and 35 points at Michigan in those saying that economic well-being in the country is unjustly distributed. The shift since 1974 here is greater than on any other economic or political item.

\section{Attitudes Toward Personal Morals}

Table 5 has six items on personal morals, which were asked after 1974. The first three are on sex, and they show decreases in tolerance of premarital sex relations and homosexuality from 1974 to 1984 . Attitudes toward pornography changed little.

The fourth item depicts a sharp reduction in those agreeing that marijuana sale and use should be legalized-31 percentage points at Dartmouth and 37 at Michigan.

\footnotetext{
${ }^{3}$ This hypothesis can be tested by intercorrelations. In 1984 we intercorrelated the items on free enterprise and government (Table 4) in the Michigan data and found a pattern of correlations unpredicted by similarities in trend lines since 1952. The only two correlations stronger than \pm .30 were between the first and fifth items (welfare state and labor unions) and between the sixth and seventh items (the best government governs least and government planning). Similarities in trends do not mean that items are intercorrelated.
} 


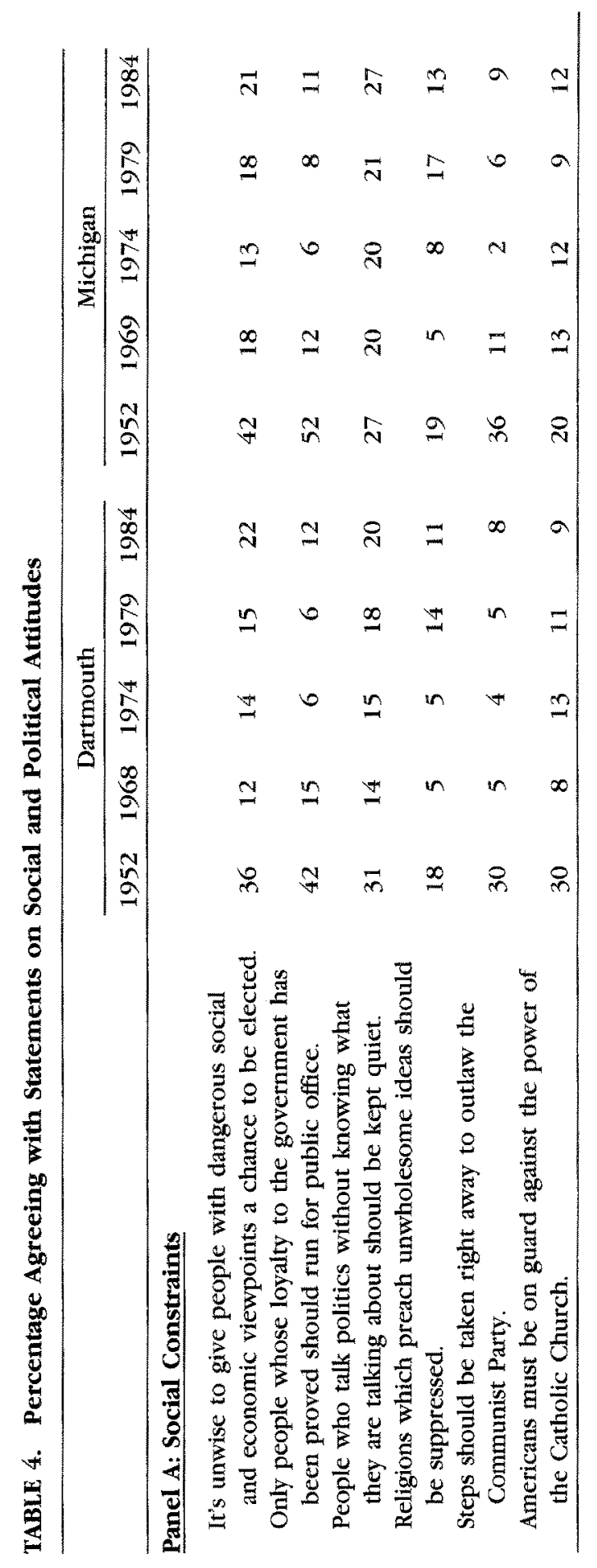




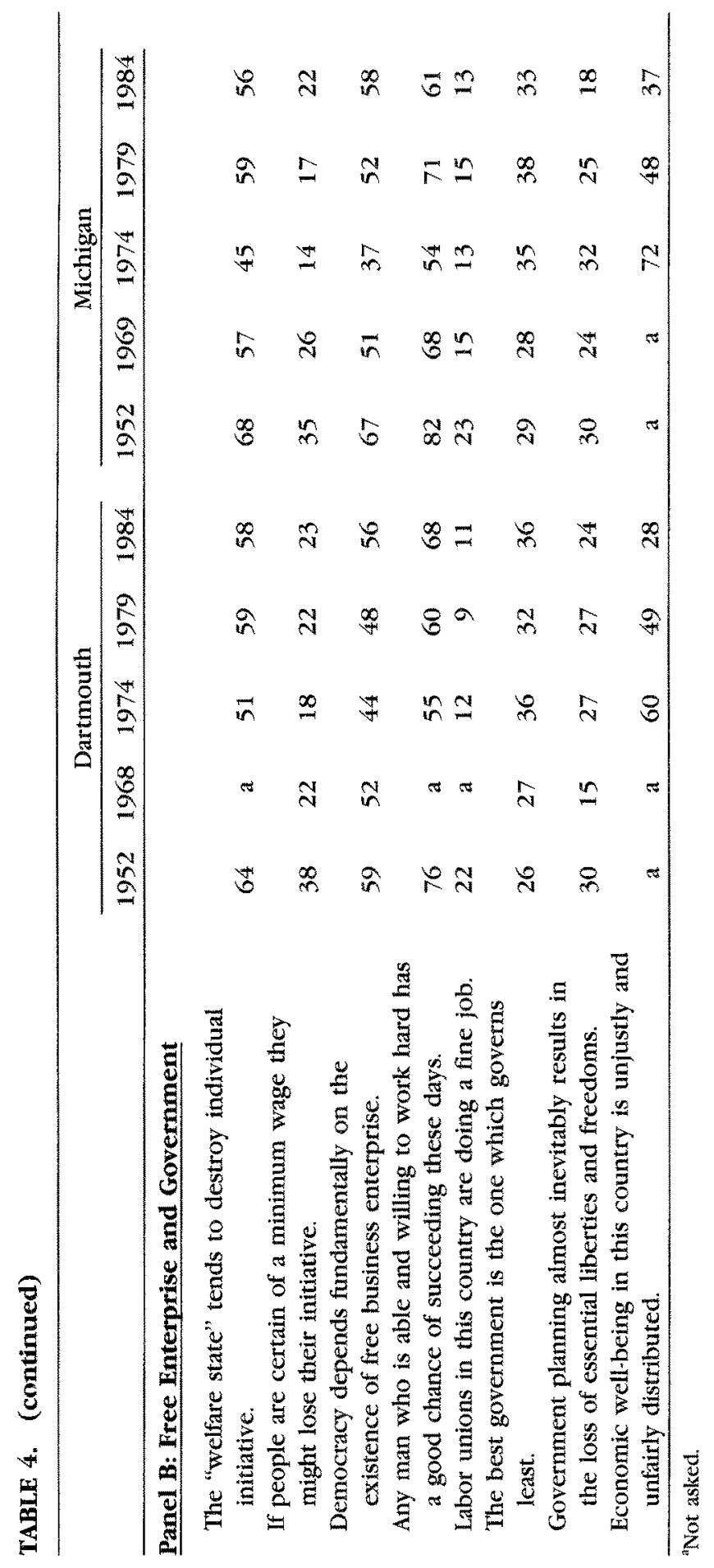


TABLE 5. Percentage Agreeing on Six Items on Personal Morals

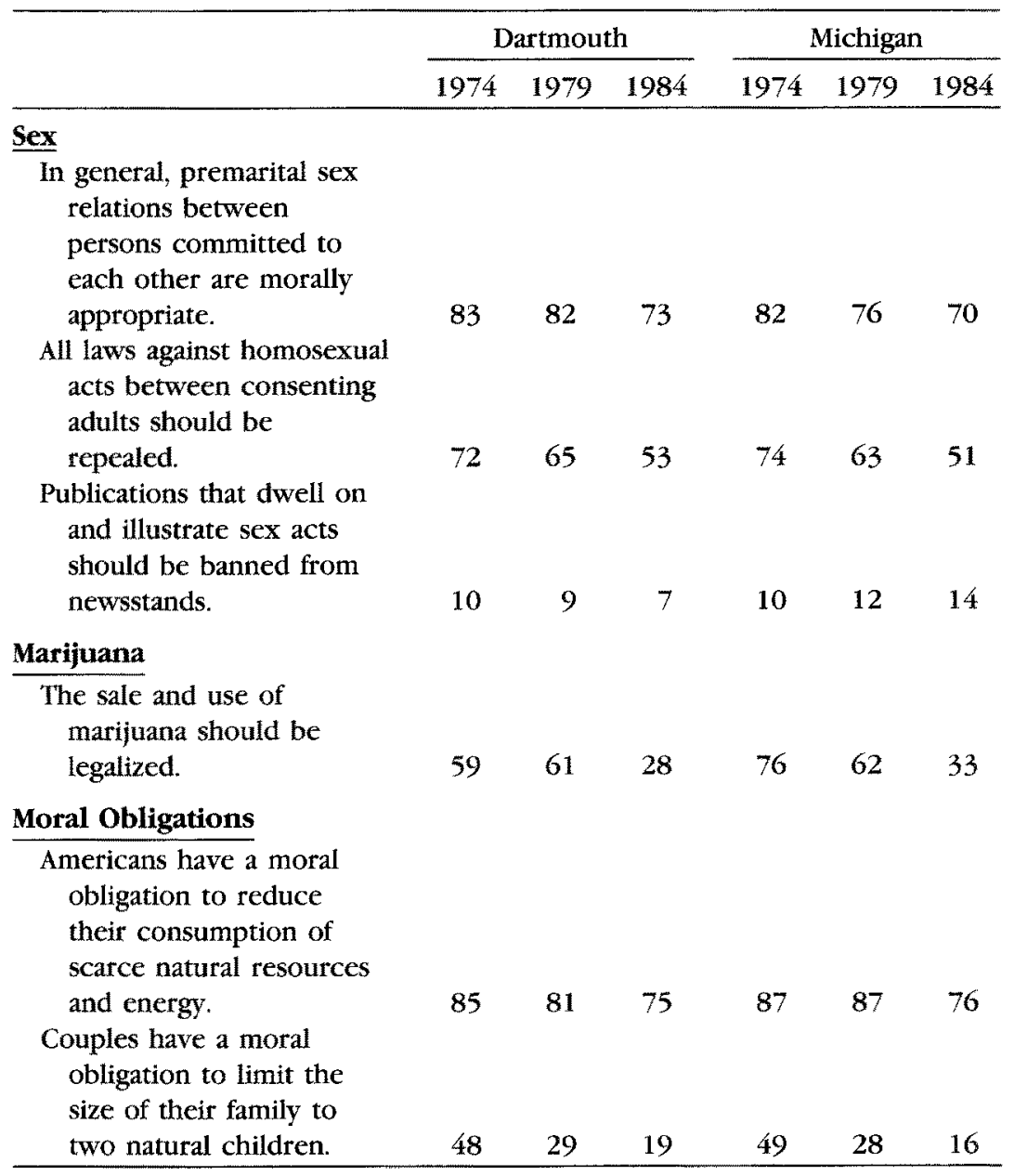

The last two items tap feelings about possible moral obligations to reduce consumption or to limit family size. On both items the belief in such moral obligations decreased from 1974 to 1984 , and in the case of limiting family size the decrease is remarkable-29 percentage points at Dartmouth and 33 at Michigan.

In sum, the last item in Table 4 and the items in Table 5 provide evidence of a set of new conservative attitudes in the early 1980s. The demand in the early 1970 s for freedom in sexual behavior and drug use has moderated in favor of increased belief in traditional morés, while at the same time the students reject responsibilities for broad social values. Between 1974 and 1984 they rejected arguments that economic well- 
being in the U.S. is unjustly distributed, and they rejected any obligations to reduce consumption of scarce resources or to reduce family size.

\section{Loglinear Models of Change}

Most of the trends in Tables 1 to 5 are readily apparent and, in some cases, quite pronounced. For this reason we did not report formal tests of the significance of changes from survey to survey, nor did we test the significance of differences between Michigan and Dartmouth students. Yet we selected four items depicting the changes in four important value areas (religion, the military, civil liberties, and free enterprise) and analyzed them across surveys and universities using loglinear models. This procedure establishes our overall conclusions more firmly in statistical terms.

The four items are:

1. Ideas about the Deity: I believe in a Divide God, Creator of the Universe (odds on this response versus other responses).

2. Anyone who serves in the armed forces is doing something worthwhile for our country (odds on agreement versus disagreement or uncertain).

3. People who talk politics without knowing what they are talking about should be kept quiet (odds on agreement versus disagreement or uncertain).

4. Democracy depends fundamentally on the existence of free business enterprise (odds on agreement versus disagreement or uncertain).

We fitted a series of hierarchical models to each of these tables and selected from them a preferred model for each, based on parsimony and fit. The models we compared all allowed the year by university association (that is, they were logit-specified), but varied in terms of the effects of year and university on the change over time. Some of the models involved no year effect, others had linear and quadratic year effect, and others involved changes that were non-monotonic or completely unconstrained.

The preferred models were different for the four items. ${ }^{4}$ Figure 1 displays the expected odds under the preferred model for each item. Significant change in responses over time was found for each. The change

\footnotetext{
${ }^{4}$ Preferred models selected for the tables involving items 1 to 4 , as described, were (YU) (UR) $\left(Y_{Q} R\right),(Y U)(U R)(Y R),\left(Y_{Q} U R\right)$, and (YUR), respectively, where $Y$ refers to Year, $U$ to University, and $R$ to Response, and subscripts denote effects of year constrained to be quadratic. (YUR) is the saturated, or trivial, model. Further information on loglinear models tested and on weighting procedures is available on request from the first author.
} 

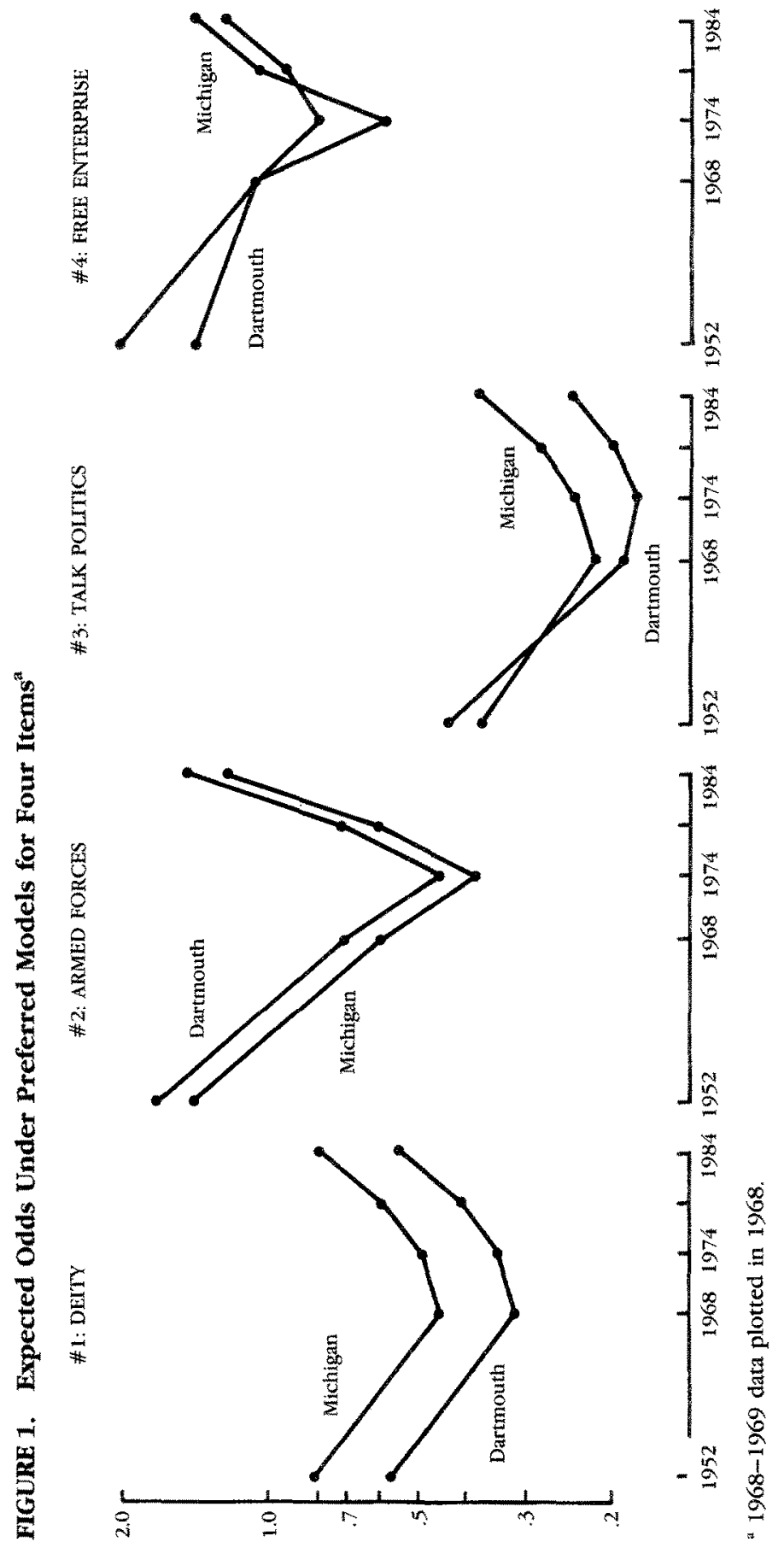
was never linear, however, nor was it quite the same from one attitude to the next. For two items ( 1 and 3 ) the change was best described by a quadratic form, but for the other two, the year effect was non-monotonic and could not be constrained. Moreover, the effect of year is similar across universities for two of the items ( 1 and 2), but dissimilar for the other two. Differences between the two universities were significant on all four items, with the differences constant on two items ( 1 and 2) but not the other two.

Two of the four items ( 2 and 4) have dramatic changes after 1974 that cannot be described by a quadratic form. We speculate that they are the product of short-term historical events: the end of the Vietnam War and the economic crisis following the 1974 gasoline shortage. On the other two attitudes, belief in a Divine God and freedom of political speech, there were probably no such strong historical influences, hence the trends are more gradual. This is only speculation, but it fits the data.

Most importantly, the changes over time defined by these preferred models are unmistakable. There was a clear shift in one direction from the 1950 s to the early 1970 s, then another shift back from the early 1970 s to the middle 1980 s.

\section{Effect of the Changing Selection of Students}

Changes in responses from one survey to the next may be due to four different factors: (1) words or phrases may change meaning over time; (2) the effect of college experience on the students may change from time to time; (3) these colleges may change their selection of students over the years, producing a different student body composition; and (4) the broader pool of college-going youth may undergo changes in values that are reflected in our samples.

We doubt if the effect of the first factor is great. We have not replicated items having ambiguous words (such as "liberal") or pertaining to specific topics such as the Cold War or Watergate. Since multiple items were used, the impact of meaning change in any one word or phrase would be small. For the second factor, we tested to see if freshman-to-senior differences varied from survey to survey and found that they are small and difficult to interpret. The changes in the responses to our surveys reflect changes in the values brought to college by the students as freshmen, not produced by the college experience itself. The third and fourth factors remain the most likely sources of changes.

To assess the third-changes in the selection of students by these colleges-we computed weighted scores in 1968-1969, 1974, 1979, and 1984 to see what the responses would have been if the backgrounds of the students had remained constant since the previous survey. That 
is, in 1968-1969 we measured the shifts in students' backgrounds at both colleges since 1952, then weighted the 1968-1969 data to reinstate the background characteristic distributions from 1952, letting us know what the responses would have been in 1968-1969 if the colleges had recruited exactly the same kinds of students as in 1952 . We did the same thing in 1974 (weighting to hold the 1968-1969 backgrounds constant) and in 1979 and 1984 (holding the 1974 and 1979 backgrounds constant).

To select the background variables on which to weight, we correlated the students' $1968-1969$ and 1974 responses with a series of background variables to determine which associations were strongest. ${ }^{5}$ On this basis at Dartmouth we weighted on family religious background, occupational prestige of the family breadwinner, major course, and Scholastic Aptitude Test verbal score in 1968, and at Michigan we weighted on family religious background, region, major course, and SAT verbal score in 1969. In 1974 and subsequent years fewer variables were weighted, since the changes in the samples were smaller. In 1974, 1979, and 1984 at Dartmouth we weighted on family religious background, major course, and race; at Michigan we weighted on family religious background, major course, and region.

As would be expected, the greatest differences between raw and weighted data occurred in 1968-1969, after the sixteen- or seventeenyear span. At Dartmouth the weighted differences were smaller than the raw differences since 1952, indicating that the changed composition of the students accounted for about a third of the observed changes in values. At Michigan the differences between raw and weighted scores in 1969 were small.

In 1974 the weighted scores at both colleges diverged little from the raw scores, and the direction of the divergences formed no clear pattern. In 1979 the weighted scores were again close to the raw scores, seldom deviating by more than one percentage point.

From 1979 to 1984 the greatest differences in the backgrounds of the Dartmouth men were a slight increase in those from Protestant families (from 41 percent to 44 percent) and a shift in major courses- 8 percentage points more either undecided or in combination majors, 6 points fewer in natural sciences, and 5 points fewer in humanities. From

\footnotetext{
${ }^{5}$ At Dartmouth we looked at immigrant generation, family religious background, father's education, mother's education, occupational prestige of family breadwinner, family religiosity, size of hometown, type of secondary school, SAT verbal and mathematics scores, major course, and age. At Michigan the list was the same except that immigrant generation and type of secondary school were deleted and family income and region of origin were added. Beginning in 1974 we restricted the list of background variables analyzed, since the replications spanned only five years each and we knew from earlier experiences which variables were the most consequential.
} 
1979 to 1984 the greatest differences in the Michigan samples were a decrease in those from Protestant families (from 37 percent to 32 percent), a decrease in those from Catholic families (from 33 percent to 29 percent), an increase in those from mixed-religious or nonreligious families (from 16 percent to 24 percent), a decrease in those from Detroit or its SMSA ( 48 percent to 34 percent), an increase in those from elsewhere in Michigan ( 27 percent to 34 percent), an increase in outof-state students (from 24 percent to 32 percent), an increase in those either undecided or in combination majors (from 24 percent to 32 percent), and a decrease in natural science majors (from 21 percent to 15 percent).

When these 1979-1984 changes were removed through weighting, the responses changed 2 percentage points or less in all the items mentioned in this paper, with one exception-belief in a Divine God, Creator of the universe, would have been 3 points higher at Michigan in 1984. (This results from the increase in students from mixed-religious homes since 1979 and the decrease in students from Protestant or Catholic homes.) Otherwise the effects of the weighting were small and inconsistent from college to college.

We conclude that the value changes found in our replications are primarily a reflection of changes in the broader population of youth attending leading colleges and universities in America.

\section{CONCLUSIONS}

Since the weighting procedures produced little change from raw data to weighted data, we conclude that the trends shown in our tables are quite representative of broad populations of students in leading colleges. This conclusion is further substantiated by the similarities of the trends in our data and in other replication research.

After our earlier analysis of the data in 1979 (Hoge, Luna, and Miller, 1981), we concluded that there was a "return of the fifties" in some respects but not others. The fifties were characterized by privatism, religious and political conservatism, anxiety about deviant social groups, other-direction, and conformity in personal morals. As of 1979, attitudes were moving in this direction in the political, economic, and religious realms but not in the personal morals realm; attitudes about marijuana and drug use, sexual experimentation, and personal freedoms were still tending in a liberal direction, continuing the trend of the 1960s.

Now we conclude that almost all attitudes are moving in a conservative direction, and the fifties are indeed returning. Of the attitudes we have studied, all are moving toward the levels of the 1950s except two. First is other-direction, which dropped greatly after the 1950 s and never rose again. Second is political involvement, measured by the ques- 
tion about whether the respondent ever gets as worked up about something in politics as about something in his or her personal life. The level of political involvement, by this measure, was very low in 1952. It rose during the 1960s but thereafter did not fall very much. In sum, the extreme personal conformity and political quietism of the fifties have not returned, but all the other attitudes are moving toward the fifties or have already arrived there.

An unexpected finding of our recent surveys was the rapidity of attitude change in several areas. In Tables 4 and 5 we depicted the sharp ten-year trends-a decrease in those agreeing that economic well-being in this country is unjustly distributed, a decrease in those saying that marijuana use should be legalized, and a decrease in those saying that American couples have a moral obligation to limit family sizes. The common element here is conventionality and privatism. Seldom has college student attitude trend research found such rapid trends.

The interpretation that American colleges in the late 1980s are seeing a return of the fifties is correct. Administrators may expect a reappearance of various motifs of the fifties to campuses, such as reduced idealism, reduced concern about civil liberties, reduced tolerance of deviant behavior, reduced interest in the broad questions of human life and destiny, increased religion, increased preoccupation with the private sphere of life, and more numerous frivolous activities.

\section{REFERENCES}

Astin, Alexander $W$., Kenneth $C$. Green, William S. Korn, and Mary Jane Maier

1985 The American Freshman: National Norms for Fall 1985. Los Angeles: UCLA Cooperative Institutional Research Program.

Carter, R. T. and William E. Sedlacek

1983 "Sex differences in student attitudes and behavior toward drugs over a decade." Research Report \#8-83. College Park, MD: University of Maryland Counseling Center.

Cook, A. S., J. B. West, and

\section{T. J. Hamner}

1982 "Changes in attitudes toward parenting among college women: 1972 and 1979 samples." Family Rela-

Erikson, Erik H. tions 31:109-113.

1959 "Identity and the life cycle." Psy. chological Issues 1:1-171.
Feldman, Kenneth A. and Theodore Newcomb

1969 The Impact of College on Students. San Francisco: Jossey-Bass.

\section{Flacks, Richard}

1971 Youth and Social Change. Chicago: Markham.

Foster, Julian and Durward Long, eds.

1970 Protest! Student Activism in America. New York: William Morrow,

Goldsen, Rose K., Morris Rosenberg,

Robin M. Williams, Jr., and Edward A.

Suchman

1960 What College Students Think. Princeton: Van Nostrand.

Hartle, Terry W, and John Taylor

1985 "What's big on campus." Public Opinion 8:49-53.

Hastings, Philip $\mathrm{K}$. and Dean R. Hoge

1986 "Religious and moral attitude trends among college students, 1948-84." Social Forces 65:370-377. 
Hildebrand, M. and S. Abramowitz

1984 "Sexuality on campus: Changes in attitudes and behavior during the 1970s." Journal of College Student Personnel 25:534-538.

Hoge, Dean $\mathbf{R}$.

1974 Commitment on Campus: Changes in Religion and Values Over Five Decades. Philadelphia: Westminster.

Hoge, Dean R., Cynthia L. Luna, and

David K. Miller

1981 'Trends in college students' values between 1952 and 1979: A return of the fifties?" Sociology of Education 54:263-274.

Jacob, Philip E.

1957 Changing Values in College. New York: Harper.

Johnston, Lloyd D., Jerald G.

Bachman, and Patrick M. O'Malley

1985 Monitoring the Future 1984. Ann Arbor, MI: Institute for Social Research.

Katchadourian, Herant A. and

John Boli

1985 Careerism and Intellectualism Among College Students. San Francisco: Jossey-Bass.

Levine, Arthur

1980 When Dreams and Heroes Died: A Portrait of Today's College Student. San Francisco: Jossey-Bass.

\section{Lipset, Seymour Martin}

1971 Rebellion in the University. Chicago: University of Chicago Press.

Manese, Jeanne $\mathrm{E}$. and William $\mathrm{E}$.

Sedlacek

1983 "Changes in religious behavior and attitudes of college students by race and sex over a ten year period." Report \#9-83. College Park, MD: University of Maryland Counseling Center.

Martinez, Alyce C. and William E. Sedlacek

1983 "Changes in the social climate of a college campus over a decade." College and University 58:254-259.

Riesman, David, Nathan Glazer, and

Reuel Denney

1950 The Lonely Crowd. New Haven, CT: Yale University Press.

Rosenberg, Morris

1957 Occupations and Values. Glencoe, IL. Free Press.

Srole, Leo

1956 "Social integration and certain correlates: An exploratory study." American Sociological Review 21:709-716.

Yankelovich, Daniel

1974 The New Morality: A Profile of American Youth in the 70s. New York: McGraw-Hill. 